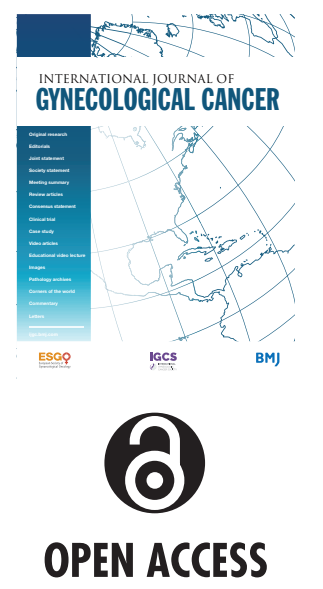

${ }^{1}$ University of California San Diego, La Jolla, California, USA ${ }^{2}$ Gynecologic Oncology, Fudan University Shanghai Cancer Center, Shanghai, China ${ }^{3}$ Radiation Oncology, Homi Bhabha Cancer Hospital and Research Centre, Visakhapatnam, Andhra Pradesh, India ${ }^{4}$ University of Buenos Aires, Buenos Aires, Argentina ${ }^{5}$ Maria Skłodowska-Curie Memorial Cancer Center, Gliwice, Poland ${ }^{6}$ Radiation Therapy Center, Okinawa Chubu Hospital, Uruma, Okinawa, Japan

Correspondence to Dr Jyoti S Mayadev, University of California San Diego, La Jolla, California, USA; jmayadev@ucsd.edu

Received 1 September 2021 Accepted 14 December 2021

A Check for updates

(C) IGCS and ESGO 2022. Re-use permitted under CC BY-NC. No commercial re-use. Published by BMJ.

To cite: Mayadev JS, Ke G, Mahantshetty U, et al. Int J Gynecol Cancer 2022;32:436445.

\title{
Global challenges of radiotherapy for the treatment of locally advanced cervical cancer
}

\author{
Jyoti S Mayadev, ${ }^{1}$ Guihao Ke, ${ }^{2}$ Umesh Mahantshetty, ${ }^{3}$ Marcos David Pereira, ${ }^{4}$ Rafal Tarnawski (D) , \\ Takafumi Toita ${ }^{6}$
}

\section{ABSTRACT}

Cervical cancer represents a significant portion of the global cancer burden for women, with low- and middleincome countries carrying the bulk of this burden. Additionally, underserved populations in countries with sufficient resources may have a higher incidence of cervical cancer and poorer outcomes. Concurrent chemoradiotherapy is the standard-of-care treatment for locally advanced cervical cancer, which includes patients with stage IB3 to IVA disease, and it is effective for many patients; however, cervical cancer-related mortality remains high. The critical nature of cervical cancer treatment is underscored by the recent launch of the World Health Organization global initiative to accelerate the elimination of cervical cancer using a tripleintervention strategy of increased vaccination, screening, and treatment. The initiative calls for $90 \%$ of all patients diagnosed with cervical cancer to receive the appropriate treatment, but to reach this global goal there are significant barriers related to radiotherapy that must be addressed. We discuss and review evidence of the lack of adherence to guideline-recommended treatment, brachytherapy underutilization, limited access to radiotherapy in low- and middle-income countries, as well as regional limitations within high-income countries, as the major barriers to radiotherapy treatment for locally advanced cervical cancer. We further review ways these barriers are currently being addressed and, in some cases, make additional recommendations to address these issues. Finally, despite receiving recommended treatments, many patients with locally advanced cervical cancer have a poor prognosis. With effective administration of current standards of care, the global community will be able to shift focus to advancing treatment efficacy for these patients. We review several types of therapies under clinical investigation that are additions to concurrent chemoradiotherapy, including immune checkpoint inhibitors, antiangiogenic agents, DNA repair inhibitors, human papillomavirus vaccines, and radiosensitizing nanoparticles.

\section{INTRODUCTION}

Cervical cancer represents a substantial portion of the global cancer burden for women. According to 2020 global estimates, it is the fourth most commonly diagnosed cancer and the fourth leading cause of cancerrelated deaths in women. ${ }^{1}$ Countries with fewer monetary, educational, and healthcare resources have the highest cervical cancer incidence and mortality rates compared with countries with a high level of resources, such as the USA and Western European countries (Figure 1). Nearly $84 \%$ of global cervical cancer cases and $88 \%$ of all deaths due to cervical cancer occur in countries with a low human development index (a summary measure of average achievement of key areas of human development, including a long and healthy life, knowledge, and decent standard of living). ${ }^{2}$ Without effective cervical cancer screening programs, many women in low-resource countries are diagnosed with invasive disease. However, even countries with sufficient resources can have underserved populations with a higher incidence of cervical cancer and poorer outcomes.

Treatment for invasive cervical cancer is stratified by stage of disease as determined by the International Federation of Gynecology and Obstetrics (FIGO) ${ }^{3}$ or the American Joint Committee on Cancer/Union for International Cancer Control TNM classification systems. ${ }^{4}$ These staging criteria were last updated in 2018 and 2021, respectively; however, some current treatment guidelines from authoritative clinical organizations use earlier versions of the FIGO and TNM criteria. For locally advanced cervical cancer, treatment can involve surgery, chemotherapy, and/or radiotherapy, with external beam radiation therapy and brachytherapy as key components. ${ }^{3}$ Concurrent chemoradiotherapy (consisting of platinum-based chemotherapy concurrent with external beam radiation therapy followed by brachytherapy) was established as the international standard of care for most stages of locally advanced cervical cancer in 1999, based on several large randomized clinical trials, that led to the US National Cancer Institute alert and clinical announcement. ${ }^{5}$ A 2017 meta-analysis ${ }^{6}$ and recent large phase III clinical trial ${ }^{7}$ have upheld the benefits of concurrent chemoradiotherapy over radiotherapy alone. The implementation of intensitymodulated radiotherapy and image-guided adaptive three-dimensional brachytherapy have further improved outcomes and reduced injury to adjacent organs.

Although effective treatment is established, cervical cancer-related mortality remains high. Recently, the World Health Organization (WHO) launched a global initiative to accelerate the elimination of cervical cancer using a triple-intervention strategy of increased vaccination, screening, and treatment. 

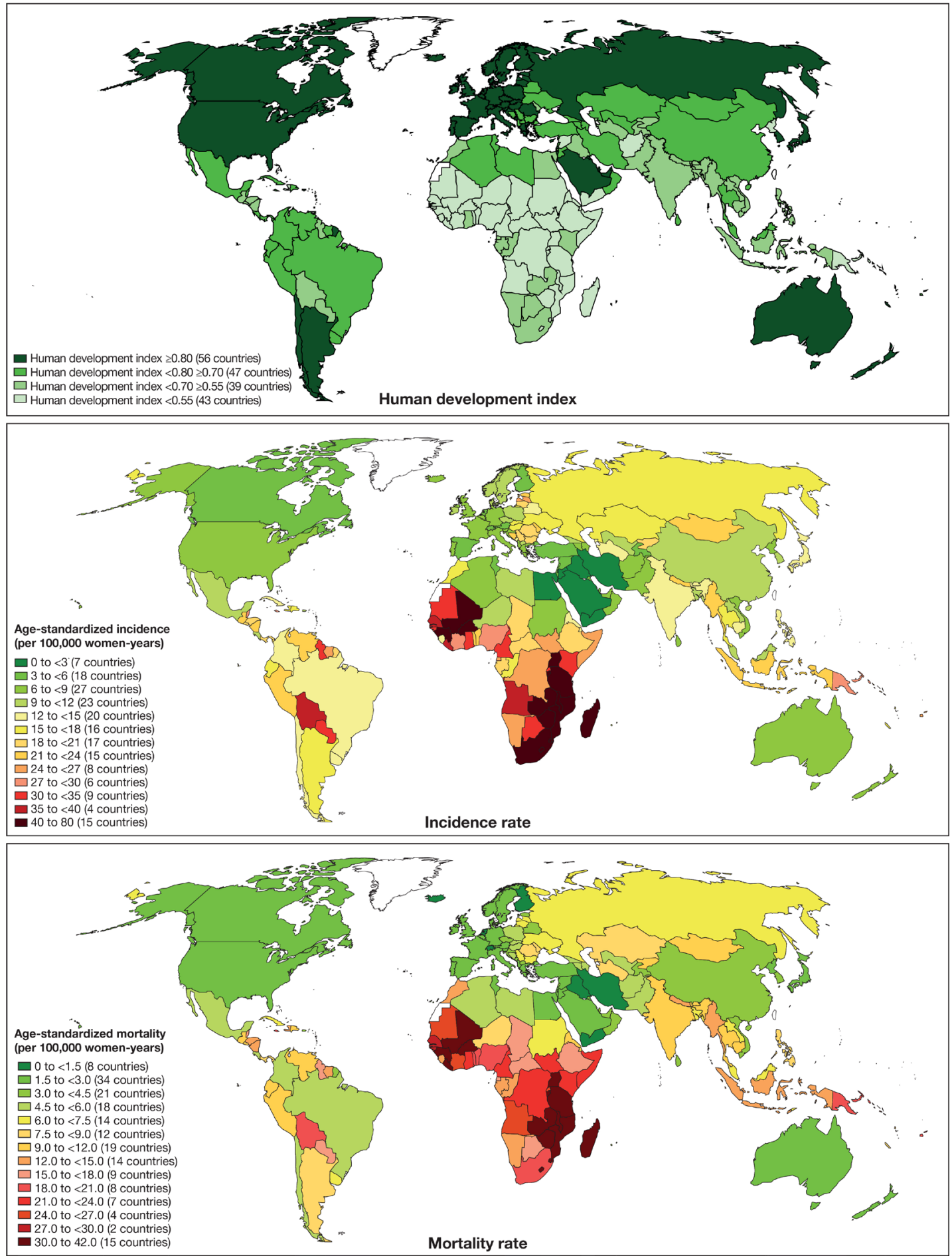

Figure 1 Relation of human development index to cervical cancer incidence and mortality. Reproduced with permission from Arbyn et al, Figures 1 and 2 and Supplemental Figure $1 .{ }^{2}$ Countries with a lower human development index also tend toward higher cervical cancer incidence and mortality rates. Incidence and mortality were estimated for 2018. The original sources for the human development index were United Nations Development Programme, New York, 2016 and International Agency for Research on Cancer, Lyon, 2018.

The triple strategy is projected to reduce cervical cancer-related mortality by at least $88.9 \%$ in low- and lower-middle-income countries over the next 50 years. ${ }^{8}$ The WHO calls for $90 \%$ of all patients diagnosed with cervical cancer to receive the appropriate treatment. To reach this global goal, it is critical to identify and address barriers and inconsistencies in treatment.
As a multinational group of radiation oncologists, we review the challenges faced in delivering radiotherapy for locally advanced cervical cancer and how they are currently being addressed (Figure 2). A key issue is the underutilization of recommended treatment, even among high-resource countries. For example, 55\% of patients with locally advanced cervical cancer did not receive 


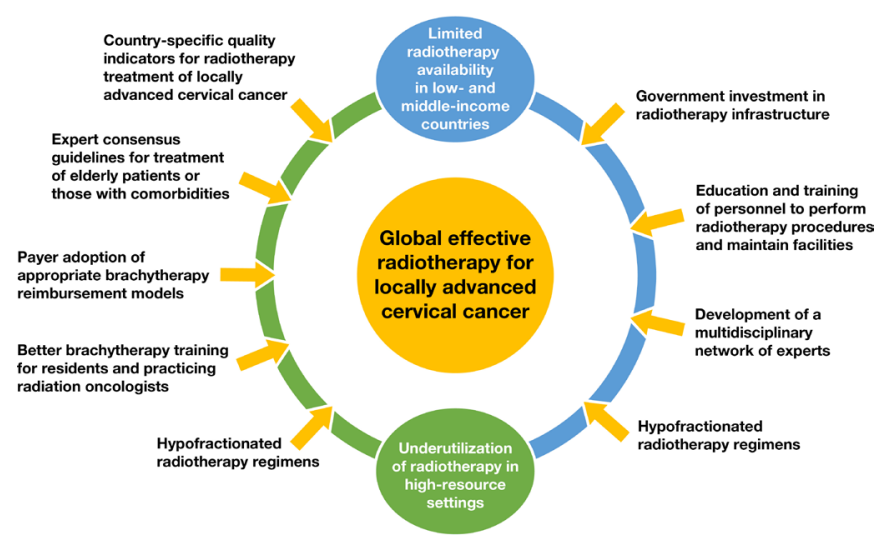

Figure 2 Challenges and solutions to achieving effective radiotherapy for locally advanced cervical cancer. The inner circle represents the goal, the outer ring shows barriers to the goal, and the outside text are actions/ideas needed to overcome barriers.

brachytherapy after external beam radiation therapy between 2004 and 2014 in California, which led to a greater risk of death from cervical cancer (hazard ratio 1.16, $\mathrm{p}=0.0330$ ). ${ }^{9}$ Additionally, many low-resource countries lack the healthcare infrastructure and facilities to administer recommended therapies, necessitating adaptation of treatment guidelines for low-resource situations. While there are many other barriers to effective use of radiotherapy in locally advanced cervical cancer (Table 1), we find the issues of underutilization and limited access as key to preventing global effective radiotherapy use for locally advanced cervical cancer. Despite receiving recommended treatments, patients with locally advanced cervical cancer have a poor prognosis as seen in the 5 year disease-free survival and overall survival of $50-70 \% .{ }^{70}$ With effective administration of current standards of care, the global community will be able to shift focus to advancing treatment efficacy for patients with poor prognosis of locally advanced cervical cancer and standardize quality for all patients with locally advanced cervical cancer.

\section{Adherence to Guideline-Recommended Treatment in High- Resource Countries}

Underutilization of standard-of-care radiotherapy treatments in locally advanced cervical cancer has been identified in some highresource countries. In Australia, Japan, and France, about 50\% of patients with locally advanced cervical cancer did not receive guideline-adherent treatment, with approximately 20-25\% not given brachytherapy. ${ }^{11-13}$ In all studies, consideration of a patient's general health likely contributed to non-adherence. For example, in Japan, comorbidities were cited as the most frequent reason for not providing guideline-recommended treatment. ${ }^{13}$ Clinical trials often do not include patients with high-risk comorbidities or poor performance status; these traits may be more frequently observed in clinical practice (eg, elderly patients) and contribute to lack of adherence to guideline-recommended treatment.

One approach to promote guideline-recommended radiotherapy treatment for locally advanced cervical cancer is the development of quality-of-care indicators. Quality indicators allow physicians to evaluate their practices against the guidelines and each other, encouraging optimal care for patients. To our knowledge, there is only one published set of quality indicators specifically for radiotherapy treatment of locally advanced cervical cancer, in Canada. ${ }^{14}$ Furthermore, to address underutilization in specific types of patients with locally advanced cervical cancer, such as older adults or those with certain comorbidities, we recommend development of expert consensus guidelines on management of locally advanced cervical cancer in these scenarios. Ultimately, clinical trials should be initiated in these populations to close the data gap on appropriate treatments.

While the extensive international collaboration to investigate ideal protocols for external beam radiation therapy and image-guided adaptive brachytherapy in the EMBRACE trials has led to more consistent radiation doses and techniques across institutions, some inconsistency in adherence remains. ${ }^{1516}$ One example is the welldocumented underutilization of brachytherapy for locally advanced cervical cancer treatment in some developed countries, including the USA. ${ }^{17}$ While data in Europe are lacking, brachytherapy leaders in Austria, Czech Republic, Italy, Hungary, Poland, and the UK agreed that its use is declining. ${ }^{18}$ This is concerning, as underutilization of brachytherapy has a clear adverse effect on survival in locally advanced cervical cancer. ${ }^{919}$

Reasons for this decline across nations with sufficient access to brachytherapy are multifactorial. The total time and labor required to execute modern brachytherapy techniques is significant compared with external beam radiation therapy in locally advanced cervical cancer treatment, ${ }^{20}$ and may contribute to the use of other boost techniques. Additionally, insufficient reimbursement systems for brachytherapy are attributed to a misunderstanding by funding institutions of the complexity and time requirement for most brachytherapy procedures; this can lead to a financial loss for radiation oncology practices performing brachytherapy. ${ }^{18} 2122$ The American Society of Radiation Oncology has developed insurance policy coverage guidance supporting a value-based payment system that would reinforce treatment decisions based on the patients' needs in line with clinical guidelines. However, this ideal policy has yet to be adopted by the US Medicare system. ${ }^{23}$ In Europe, the Innovative Partnership for Action Against Cancer released a comprehensive assessment of radiotherapy reimbursement plans across the continent, recommending a shift toward estimating costs of care using time-driven activity-based analysis

\footnotetext{
Table 1 Challenges to effective radiotherapy treatment of locally advanced cervical cancer not discussed in this review

\begin{tabular}{ll}
\hline Facility-related barriers & Significant time required to plan teletherapy treatments \\
& Cost and logistics of replacing cobalt brachytherapy units in low- and middle-income countries \\
Patient-related barriers & Cost of treatment, including monetary cost directly to the patient and additional unseen costs of \\
& supportive care, transportation, and childcare \\
& Compliance with chemoradiation regimen, including issues with distance to treatment facility \\
\hline
\end{tabular}
}


and considering a plan that would allow adoption of emerging radiotherapy techniques. ${ }^{24}$

While brachytherapy is a mandatory component of most radiation oncology residency programs in high-resource countries, surveys indicate that many brachytherapists agree residents are not receiving adequate training, and maintenance of brachytherapy skills is a barrier to its use. ${ }^{182125}$ In the USA, meeting the minimum requirement of five interstitial procedures during residency is often not enough to instill confidence in maintaining a brachytherapy practice. $^{21}$ A survey of brachytherapy education in Italy found learning opportunities were heterogenous among medical schools, prompting the Italian Association of Radiotherapy and Clinical
Oncology to support post-residency specialty courses and begin development of a unified curriculum. ${ }^{25}$

In response to the decline of brachytherapy use, several organizations are undertaking initiatives to enhance the image of brachytherapy and offer various types of training platforms. The American Brachytherapy Society launched a successful social media campaign in 2019 with the goal of empowering radiation oncologists to address brachytherapy underutilization. ${ }^{26}$ The American Brachytherapy Society is also starting a '300 in 10 ' initiative, which provides an external rotation for cervical brachytherapy to senior residents in the USA at predesignated centers of excellence to further train 300 brachytherapists in 10

\section{A}

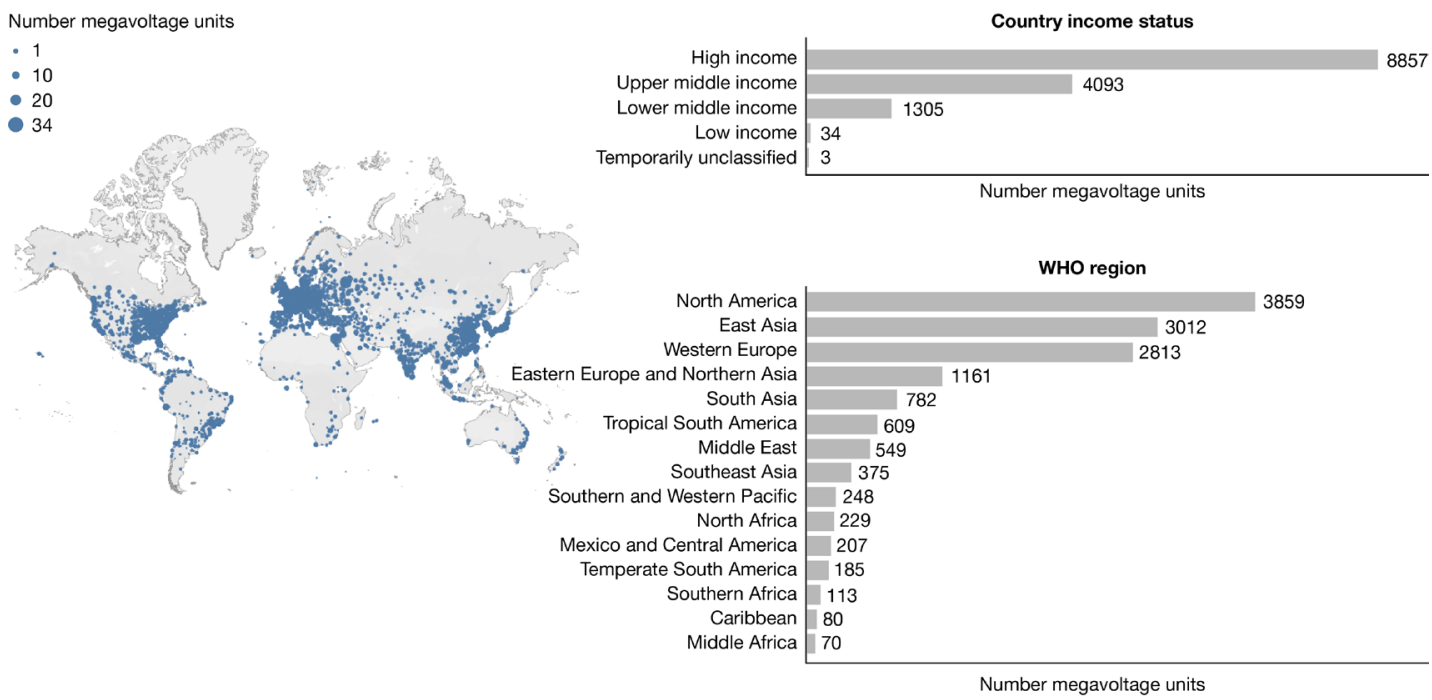

B

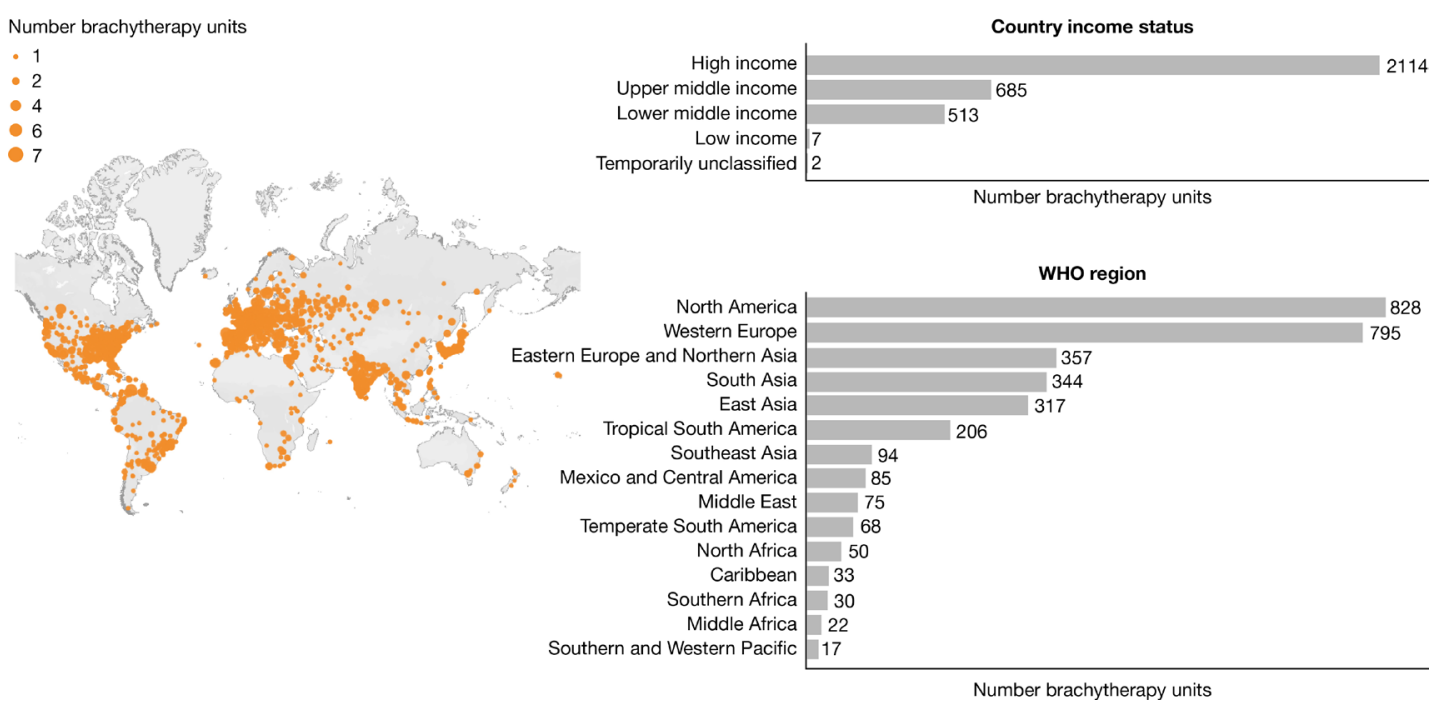

Figure 3 Distribution of megavoltage $(A)$ and brachytherapy $(B)$ equipment per the International Atomic Energy Agency Directory of Radiotherapy Centres (DIRAC) as of February 2021. Data are voluntarily submitted to DIRAC by several sources including individuals working in a radiotherapy center, national DIRAC coordinators, the International Atomic Energy Agency/ World Health Organization mailed dosimetry audit program, third-party organizations, and other sources. The International Atomic Energy Agency DIRAC website (https://dirac.iaea.org/) was accessed on March 28, 2021. Distribution of megavoltage and brachytherapy units across the globe were generated by the website and were current as of February $28,2021$. 
Table 2 Locally advanced cervical cancer treatment guidelines for low-resource settings

\begin{tabular}{ll}
\hline Guideline & Optimal treatment \\
\hline International & Stages IB2 and IIA2 \\
Atomic Energy & Concurrent chemoradiation, followed by \\
Agency 2013 & brachytherapy \\
& Stages IIB-IVA \\
& External beam radiation therapy with \\
& or without concurrent chemotherapy, \\
& followed by brachytherapy
\end{tabular}

Limited resources

Stages IB2 and IIA2

Where brachytherapy is not available, surgery followed by adjuvant radiotherapy or chemoradiation

Stages IIB-IVA

Where treatment compliance, patient health factors (eg, nutrition, performance status), or the inability to treat complications of chemoradiation are a concern, treatment with definitive radiotherapy +brachytherapy without chemotherapy is an option

3-dimensional conformal external beam Where 3-dimensional techniques are not available, radiation therapy using CT imaging is 2-dimensional treatment planning and delivery for external ideal to limit radiation to the surrounding beam radiation therapy should be based on bony landmarks organs

\section{American Society of Clinical Oncology $2016^{55}$}

Stages IB2-IVA

Concurrent pelvic chemoradiation

\author{
International \\ Federation of \\ Gynecology and \\ Obstetrics $2015^{56}$
}

\section{Stages IB2-IVA}

Radical chemoradiation, followed by brachytherapy

The total radiotherapy dose should be 80-85 EQD2 to point $A$

MRI-guided brachytherapy is optimal

\section{Stages IB2 and IIA2}

No radiotherapy or surgical experts: neoadjuvant chemotherapy, then extrafascial hysterectomy Chemotherapy and surgical experts available, no radiotherapy: neoadjuvant chemotherapy, then radical hysterectomy External beam radiation therapy available, no brachytherapy: concurrent chemoradiation, then extrafascial hysterectomy Brachytherapy available, no external beam radiation therapy: brachytherapy concurrent with chemotherapy, then radical hysterectomy

IIB and IIIA

No external beam radiation therapy or brachytherapy: neoadjuvant chemotherapy, then extrafascial or modified hysterectomy

No chemotherapy or brachytherapy: external beam radiation therapy, then extrafascial or modified hysterectomy Chemotherapy and external beam radiation therapy available, no brachytherapy: concurrent chemoradiation, then hysterectomy

IIIB to IVA

No external beam radiation therapy, chemotherapy, brachytherapy: palliative care

No external beam radiation therapy or brachytherapy: neoadjuvant chemotherapy, then hysterectomy No chemotherapy or brachytherapy: external beam radiation therapy, then hysterectomy

Chemotherapy and external beam radiation therapy available, no brachytherapy: concurrent chemoradiation, then hysterectomy

Stages IB2-IVA

Where treatment compliance, patient health factors (eg, nutrition, performance status), or the inability to treat complications of chemoradiation are a concern, treatment with definitive radiotherapy +brachytherapy without chemotherapy is an option

Where MRI is unavailable, CT or ultrasound imaging should be used to guide brachytherapy 
Table 2 Continued

\begin{tabular}{|c|c|c|}
\hline Guideline & Optimal treatment & Limited resources \\
\hline $\begin{array}{l}\text { American } \\
\text { Brachytherapy } \\
\text { Society } 2017^{57}\end{array}$ & $\begin{array}{l}\text { Locally advanced disease confined to } \\
\text { pelvis } \\
\text { External beam radiation therapy using } \\
\text { 4-field technique with blocking, dose } \\
45 \text { Gy in } 1.8 \text { Gy fractions, CT-based } \\
\text { planning is ideal } \\
\text { Chemotherapy concurrent with } \\
\text { external beam radiation therapy is } \\
\text { recommended } \\
\text { Brachytherapy should be planned with } \\
\text { 3-dimensional imaging, preferably CT, } \\
\text { and given to a minimum EQD2 of } 80 \text { Gy }\end{array}$ & $\begin{array}{l}\text { Locally advanced disease confined to pelvis } \\
\text { In the absence of custom blocking for external beam radiation } \\
\text { therapy, corner shields may be used } \\
\text { Where CT-based testing is not possible, use bony landmarks in } \\
\text { field design } \\
\text { Radiotherapy alone may be appropriate if access to } \\
\text { chemotherapy is limited or due to patient status/comorbidities } \\
\text { is prohibitive } \\
\text { Brachytherapy planning with 2-dimensional imaging, or, if } \\
\text { 2-dimensional imaging is not available, planning to point A with } \\
\text { modifications based on tumor volume and organ-at-risk doses }\end{array}$ \\
\hline $\begin{array}{l}\text { National Cancer } \\
\text { Grid India } 2018^{58}\end{array}$ & $\begin{array}{l}\text { Stages IB2-IVA } \\
\text { Concurrent pelvic chemoradiation, } \\
\text { using intensity-modulated radiotherapy, } \\
\text { followed by chemotherapy or MRI- } \\
\text { based brachytherapy }\end{array}$ & $\begin{array}{l}\text { Stages IB2-IVA } \\
\text { Concurrent pelvic chemoradiation, followed by brachytherapy, } \\
\text { but with 3-dimensional external beam radiation therapy and } \\
\text { 2-dimensional brachytherapy techniques }\end{array}$ \\
\hline
\end{tabular}

$\mathrm{CT}$, computed tomography; EQD2, equi-effective dose to 2 Gy per fraction; MRI, magnetic resonance imaging.

years. ${ }^{27}$ Increasing awareness of brachytherapy and introducing creative educational opportunities, such as the combination of didactic learning and simulation-based brachytherapy training, may increase interest in and exposure to brachytherapy. ${ }^{28}$ The International Atomic Energy Agency is currently developing a comprehensive document on the competencies needed for brachytherapy professionals, aimed at providing an international standard for assessing brachytherapy education. ${ }^{29}$

Shorter brachytherapy regimens may help reduce the overall time and personnel required for brachytherapy treatment. During the coronavirus disease 2019 (COVID-19) pandemic, hypofractionated radiotherapy regimens have been used with some success. ${ }^{30}$ Datta et al recently identified a combination of hypofractionated radiotherapy \pm longer working hours to improve overall radiotherapy coverage with existing facilities in 43 countries in Asia, where economic development has been significantly impacted by the pandemic. ${ }^{31}$ Shorter brachytherapy regimens may also help patient compliance, as there is evidence to suggest that significant psychological distress is associated with current recommended regimens. ${ }^{32}$ Two ongoing phase II trials in Mexico (NCT04070976) and Canada (HEROICC-Trial (NCT04583254)) are evaluating the efficacy and safety of hypofractionated radiotherapy doses in concurrent chemoradiotherapy for locally advanced cervical cancer.

\section{Limited Access to Radiotherapy in Low- and Middle-Income Countries}

For low- and middle-income countries, there is a deficit of radiotherapy facilities based on the estimated need. While some highresource countries have a surplus of radiotherapy coverage, some low- and middle-income countries may have no facilities, with coverage increasing linearly with gross national income. ${ }^{33}$ In 2014, 55 of 139 low- and middle-income countries had no radiotherapy facilities; Africa and Oceania were the most affected. ${ }^{34}$ In Latin America, only three countries met the International Atomic Energy Agency recommendation of one megavoltage machine per 250000 population, and there was only one brachytherapy machine per 2.4 million people for the entire region, with $\sim 50 \%$ of machines located in Brazil and Mexico. ${ }^{35}$ No countries with radiotherapy facilities in Africa met International Atomic Energy Agency recommendations for megavoltage machines, and only one brachytherapy machine per 15.4 million people was available for the entire continent, with $>70 \%$ of all machines in only six countries. ${ }^{35}$ In 2017 , India reported a deficit of radiotherapy machines at 1 per 2.1 million people, with a growing need that would only widen this gap. ${ }^{36} \mathrm{~A}$ map of the distribution of megavoltage and brachytherapy units as of February 2021 (Figure 3) shows that disparities between and within geographical regions and individual countries are still prevalent.

For countries that have a higher proportion of radiotherapy facilities, there can be disparity in the regional density of facilities within a country. For example, although China has made strides in increasing the overall ratio of radiotherapy facilities per million people (0.75 in 2006 to 1.49 in 2015), these resources are limited in rural areas like Ningxia (0.87 radiotherapy facilities per million people); by contrast, in modern cities like Beijing (3.07 radiotherapy facilities per million people), advanced treatment is available and delivered in an appropriate timeframe. ${ }^{37}$ Similar trends in regional density of facilities have been reported in Argentina and India. ${ }^{38}$

Multiple factors contribute to the shortage of radiotherapy facilities. Overuse of limited facilities can lead to frequent maintenance requirements, which temporarily further reduces the radiotherapy capacity of a region. Timely investment by low- and middle-income countries in radiotherapy facilities and required personnel is critical to achieve the WHO goal of appropriately treating $90 \%$ of all patients with cervical cancer. The International Atomic Energy Agency has been a key resource in bringing radiotherapy to low- and middleincome countries over the years through many initiatives and multiple guidance documents. ${ }^{29} 4041$ The initiation or scale-up of radiotherapy programs requires a level of readiness in low-resource countries or regions, which is supported by strong national commitments to building infrastructure that includes adequate radiotherapy 
Table 3 Ongoing trials of investigational therapies for locally advanced cervical cancer using concurrent chemoradiotherapy as a backbone

\begin{tabular}{|c|c|c|c|}
\hline $\begin{array}{l}\text { Trial name/ } \\
\text { identification }\end{array}$ & Investigational therapy & Concurrent chemoradiotherapy regimen & Phase \\
\hline & Immune checkpoint inhibitors & & \\
\hline $\begin{array}{l}\text { CALLA } \\
\text { NCT03830866 }\end{array}$ & $\begin{array}{l}\text { Durvalumab vs placebo } \\
\text { Concurrent with chemoradiotherapy } \\
\text { and adjuvant }\end{array}$ & $\begin{array}{l}\text { Weekly platinum-based chemotherapy + external } \\
\text { beam radiation therapy, then brachytherapy }\end{array}$ & III \\
\hline $\begin{array}{l}\text { KEYNOTE-A18 } \\
\text { NCT04221945 }\end{array}$ & $\begin{array}{l}\text { Pembrolizumab vs placebo } \\
\text { Concurrent with chemoradiotherapy } \\
\text { and adjuvant }\end{array}$ & $\begin{array}{l}\text { Weekly cisplatin + external beam radiation } \\
\text { therapy, then brachytherapy }\end{array}$ & III \\
\hline $\begin{array}{l}\text { ATEZOLACC } \\
\text { NCT03612791 }\end{array}$ & $\begin{array}{l}\text { Atezolizumab vs standard of care } \\
\text { Concurrent with chemoradiotherapy } \\
\text { and adjuvant }\end{array}$ & $\begin{array}{l}\text { Weekly cisplatin + external beam radiation } \\
\text { therapy, then brachytherapy }\end{array}$ & II \\
\hline $\begin{array}{l}\text { BrUOG } 355 \\
\text { NCT03527264 }\end{array}$ & $\begin{array}{l}\text { Nivolumab } \\
\text { Concurrent with chemoradiotherapy } \\
\text { Adjuvant to chemoradiotherapy } \\
\text { Concurrent with chemoradiotherapy } \\
\text { and adjuvant }\end{array}$ & $\begin{array}{l}\text { Weekly cisplatin }+ \text { external beam radiation } \\
\text { therapy* }\end{array}$ & ॥ \\
\hline NCT02635360 & $\begin{array}{l}\text { Pembrolizumab } \\
\text { Concurrent with chemoradiotherapy } \\
\text { Adjuvant to chemoradiotherapy }\end{array}$ & Weekly cisplatin, then brachytherapy only & ॥ \\
\hline \multirow[t]{2}{*}{ NCT03738228 } & $\begin{array}{l}\text { Atezolizumab } \\
\text { - Neoadjuvant and concurrent with } \\
\text { chemoradiotherapy } \\
\text { - Concurrent with chemoradiotherapy }\end{array}$ & $\begin{array}{l}\text { Weekly cisplatin + external beam radiation } \\
\text { therapy, then brachytherapy }\end{array}$ & I \\
\hline & Antiangiogenic therapies & & \\
\hline NCT04138992 & $\begin{array}{l}\text { Bevacizumab vs standard of care } \\
\text { Neoadjuvant bevacizumab }+ \\
\text { chemotherapy and concurrent with } \\
\text { chemoradiotherapy } \\
\text { - Concurrent with chemoradiotherapy }\end{array}$ & $\begin{array}{l}\text { Weekly cisplatin + external beam radiation } \\
\text { therapy, then brachytherapy }\end{array}$ & $\| / I I I$ \\
\hline \multirow[t]{2}{*}{ NCT04121975 } & $\begin{array}{l}\text { Endostar } \\
\text { - Concurrent with chemoradiotherapy }\end{array}$ & $\begin{array}{l}\text { Weekly cisplatin + external beam radiation } \\
\text { therapy }\end{array}$ & $\|$ \\
\hline & Ribonuclease reductase inhibitor & & \\
\hline \multirow[t]{2}{*}{ NCT02466971 } & $\begin{array}{l}\text { Triapine vs standard of care } \\
\text { - Concurrent with chemoradiotherapy }\end{array}$ & $\begin{array}{l}\text { Weekly cisplatin + external beam radiation } \\
\text { therapy, then brachytherapy }\end{array}$ & III \\
\hline & HPV vaccine & & \\
\hline \multirow[t]{2}{*}{$\begin{array}{l}\text { IMMUNOCERV } \\
\text { NCT04580771 }\end{array}$} & $\begin{array}{l}\text { PDS0101 } \\
\text { Concurrent with chemoradiotherapy } \\
\text { and adjuvant }\end{array}$ & Weekly cisplatin + radiotherapy* & $\|$ \\
\hline & Radiosensitizing nanoparticle & & \\
\hline $\begin{array}{l}\text { NANOCOL } \\
\text { NCT03308604 }\end{array}$ & $\begin{array}{l}\text { AGulX } \\
\text { Concurrent with radiotherapy }\end{array}$ & $\begin{array}{l}\text { Weekly cisplatin + external beam radiation } \\
\text { therapy, then brachytherapy }\end{array}$ & 1 \\
\hline
\end{tabular}

All information gathered from clinicaltrials.gov.

*Brachytherapy not specified.

HPV, human papillomavirus.

facilities and supporting systems (eg, electricity, transportation) with appropriate equitable distribution. Facilitators of successful experiences in creating high-quality radiotherapy programs in lowand middle-income countries include significant political support, development of a costed cancer plan, multiple funding sources, adoption of evidence-based practice, strategic partnerships (such as with the International Atomic Energy Agency), focus on patientcentered care, and availability of supportive technologies. ${ }^{42}$

Given the limited ability of low- and middle-income countries to train additional radiation oncologists to meet the growing need for radiotherapy facilities, a deficit of 8900 full-time equivalent employees is projected in $20300^{43}$ Without properly trained staff, quality and 
safety of radiotherapy treatment is at risk. ${ }^{29}{ }^{40}$ Effective training and increased numbers of radiation technologists, nurses, medical physicists, and radiation oncologists are needed to ensure quality care in low- and middle-income countries. Successful initiatives to bring education and training to low-resource countries include several e-learning programs. ${ }^{41}{ }^{42}$ The web-based Chartrounds facilitates training and chart review of cases, connecting radiation specialists and local practitioners. In the first year of implementation in India, $76 \%$ of participants agreed that the sessions would contribute to a change in their radiation oncology practice. ${ }^{44}$ Train-the-trainer-style series from organizations such as Radiating Hope and Royal Australian and New Zealand College of Radiologists, European Society for Radiotherapy and Oncology, and International Atomic Energy Agency are another avenue for disseminating current knowledge and practical advice. Partnerships between medical institutions in high- and low-resource countries can also facilitate development of radiation oncology expertise.

While many low- and middle-income countries are working toward improved access to cervical cancer treatments, the most effective treatments may not be available. Therefore, several organizations have provided cervical cancer treatment guidelines targeted to regions with various levels of treatment availability; however, recommendations are often based on expert consensus as opposed to strong clinical evidence (Table 2). Until adequate radiotherapy resources become available, patients with locally advanced cervical cancer treated per these limitedresource recommendations will continue to have poorer prognoses compared with those treated with an ideal concurrent chemoradiotherapy regimen.

\section{Future Directions in Concurrent Chemoradiotherapy for Locally Advanced Cervical Cancer}

More than half of patients with locally advanced cervical cancer who are treated with concurrent chemoradiotherapy will develop recurrent disease or distant metastasis; thus, continued research for improved treatment is needed. Importantly, recent results from the phase III OUTBACK trial showed adjuvant chemotherapy following concurrent chemoradiotherapy did not provide a survival benefit at 5 years compared with concurrent chemoradiotherapy alone in patients with locally advanced cervical cancer, and there were significantly more adverse events in the adjuvant chemotherapy group. ${ }^{45}$ Combinations of concurrent chemoradiotherapy with immunotherapies, targeted therapies, or other novel therapies are actively being investigated (Table 3).

Combining concurrent chemoradiotherapy and programmed death-1/programmed death ligand-1 blockade with immune checkpoint inhibitors can enhance CD8 $+\mathrm{T}$ cell immune response and recruitment to the tumor site. This combination has provided improved outcomes in patients with advanced non-small cell lung cancer in the PACIFIC trial of durvalumab given after concurrent chemoradiotherapy, which led to its approval in the USA for this indication. ${ }^{46}$ More recently, the phase III KEYNOTE-826 trial of pembrolizumab given in combination with platinum-based chemotherapy with or without bevacizumab reported improved progression-free survival and overall survival for patients with programmed death ligand-1-positive recurrent/metastatic cervical cancer. ${ }^{47}$ Ongoing studies of concurrent chemoradiotherapy in combination with immune checkpoint inhibitors in patients with locally advanced cervical cancer are assessing the sequence of treatments and overall efficacy and safety (Table 3 ) ${ }^{48-50}$

Other unique concurrent chemoradiotherapy combinations are being tested. Although decreasing tumor vasculature with antiangiogenic agents appears counterintuitive with concurrent chemoradiotherapy, since chemotherapy and radiation depend on a functioning vascular system, antiangiogenic agents may enhance chemoradiation through normalization of the vasculature surrounding the tumor. ${ }^{51}$ DNA repair inhibitors, such as triapine, and inorganic radiosensitizing nanoparticles, such as AGulX, are being combined with concurrent chemoradiotherapy with the rationale that these agents would enhance the effects of chemoradiationmediated cell death. ${ }^{52}{ }^{53}$ Finally, stimulation of T-cell responses by therapeutic human papillomavirus vaccines, such as PDS0101, may enhance the effects of concurrent chemoradiotherapy for treatment of locally advanced cervical cancer.

\section{CONCLUSION}

Radiotherapy is a critical component of locally advanced cervical cancer treatment, with both external beam radiation therapy and brachytherapy essential for success. In regions with sufficient or surplus radiotherapy access, training insufficiency, as well as reimbursement schemes that do not appropriately account for the significant time and labor required for radiotherapy in locally advanced cervical cancer, contribute to underutilization and jeopardize patient survival. In regions with lower resource levels, disparity in access to basic radiotherapy services is a major challenge to providing standard-of-care treatment. Important efforts by international organizations and individual countries have improved radiotherapy access, yet the current rate of improvement will not be enough to meet the WHO goal of treating $90 \%$ of cervical cancer patients globally. The strategies presented herein, combined with the potential for a new generation of therapies in combination with concurrent chemoradiotherapy, will hopefully increase global access and implementation of an improved treatment armamentarium to address the needs and goals for patients with locally advanced cervical cancer.

Acknowledgements Medical writing support, which was in accordance with Good Publication Practice (GPP3) guidelines, was provided by Nicole Seneca, PhD, of Parexel (Hackensack, $\mathrm{NJ}$ ) and was funded by AstraZeneca.

Contributors All authors made substantial contributions to the conception, analysis, interpretation of data, and the drafting and revision of the manuscript for important intellectual content. All authors read and approved the final manuscript.

Funding Medical writing support provided by Parexel was funded by AstraZeneca. The authors had full control over the content and development of this article. AstraZeneca did not influence the opinion of the authors; a review of the final draft was performed for scientific accuracy and intellectual property.

Competing interests JM reports honoraria from Varian Medical Systems; consulting/advisory fees from the GOG foundation, NRG oncology, AstraZeneca, Agenus Bio; research funding from NRG Oncology; and travel/accommodation support from the GOG foundation. MDP reports honoraria and travel/ accommodation support from Merck, Serono, and MSD; travel/accommodation support from Gador; and employment as a medical advisor for IQVIA.

Patient consent for publication Not applicable.

Ethics approval This study does not involve human participants.

Provenance and peer review Commissioned; internally peer reviewed.

Open access This is an open access article distributed in accordance with the Creative Commons Attribution Non Commercial (CC BY-NC 4.0) license, which 


\section{Review}

permits others to distribute, remix, adapt, build upon this work non-commercially, and license their derivative works on different terms, provided the original work is properly cited, an indication of whether changes were made, and the use is noncommercial. See: http://creativecommons.org/licenses/by-nc/4.0/.

\section{ORCID iD}

Rafal Tarnawski http://orcid.org/0000-0001-6802-5093

\section{REFERENCES}

1 Sung H, Ferlay J, Siegel RL, et al. Global cancer statistics 2020: GLOBOCAN estimates of incidence and mortality worldwide for 36 cancers in 185 countries. CA Cancer J Clin 2021;71:209-49.

2 Arbyn M, Weiderpass E, Bruni L, et al. Estimates of incidence and mortality of cervical cancer in 2018: a worldwide analysis. Lancet Glob Health 2020;8:e191-203.

3 Bhatla N, Aoki D, Sharma DN, et al. Cancer of the cervix uteri. Int J Gynaecol Obstet 2018;143 Suppl 2:22-36.

4 Olawaiye AB, Baker TP, Washington MK, et al. The new (version 9) American Joint Committee on Cancer tumor, node, metastasis staging for cervical cancer. CA Cancer J Clin 2021;71:287-98.

5 Oncology NEWS International. NCl urges chemo-RT combination for invasive cervical cancer, 1999. Available: https://www. cancernetwork.com/view/nci-urges-chemo-rt-combination-invasivecervical-cancer [Accessed 24 Aug 2021].

6 Datta NR, Stutz E, Liu M, et al. Concurrent chemoradiotherapy vs. radiotherapy alone in locally advanced cervix cancer: a systematic review and meta-analysis. Gynecol Oncol 2017;145:374-85.

7 Shrivastava S, Mahantshetty U, Engineer R, et al. Cisplatin chemoradiotherapy vs radiotherapy in FIGO stage IIIB squamous cell carcinoma of the uterine cervix: a randomized clinical trial. JAMA Oncol 2018;4:506-13.

8 Canfell K, Kim JJ, Brisson M, et al. Mortality impact of achieving WHO cervical cancer elimination targets: a comparative modelling analysis in 78 low-income and lower-middle-income countries. Lancet 2020;395:591-603.

9 Mayadev J, Klapheke A, Yashar C, et al. Underutilization of brachytherapy and disparities in survival for patients with cervical cancer in California. Gynecol Oncol 2018;150:73-8.

10 Eifel PJ, Winter K, Morris M, et al. Pelvic irradiation with concurrent chemotherapy versus pelvic and para-aortic irradiation for high-risk cervical cancer: an update of radiation therapy oncology group trial (RTOG) 90-01. J Clin Oncol 2004;22:872-80.

11 Chiew K-L, Chong S, Duggan KJ, et al. Assessing guideline adherence and patient outcomes in cervical cancer. Asia Pac J Clin Oncol 2017;13:e373-80.

12 Espenel S, Garcia M-A, Trone J-C, et al. From IB2 to IIIB locally advanced cervical cancers: report of a ten-year experience. Radiat Oncol 2018;13:16

13 Watanabe T, Mikami M, Katabuchi H, et al. Quality indicators for cervical cancer care in Japan. J Gynecol Oncol 2018;29:e83.

14 Croke J, Fyles A, Barbera L, et al. Radiation therapy quality-ofcare indicators for locally advanced cervical cancer: a consensus guideline. Pract Radiat Oncol 2016;6:315-23.

15 Berger T, Seppenwoolde Y, Pötter R, et al. Importance of technique, target selection, contouring, dose prescription, and dose-planning in external beam radiation therapy for cervical cancer: evolution of practice from EMBRACE-I to II. Int J Radiat Oncol Biol Phys 2019;104:885-94.

16 Pötter R, Tanderup K, Kirisits C, et al. The EMBRACE II study: the outcome and prospect of two decades of evolution within the GECESTRO GYN working group and the EMBRACE studies. Clin Trans/ Radiat Oncol 2018;9:48-60.

17 Han K, Viswanathan AN. Brachytherapy in gynecologic cancers: why is it underused? Curr Oncol Rep 2016;18:26.

18 Fricker J. Brachytherapy: halting the spiral of decline. Cancerworld 2019;85:4-15.

19 Robin TP, Amini A, Schefter TE, et al. Disparities in standard of care treatment and associated survival decrement in patients with locally advanced cervical cancer. Gynecol Oncol 2016;143:319-25.

20 Bauer-Nilsen K, Hill C, Trifiletti DM, et al. Evaluation of delivery costs for external beam radiation therapy and brachytherapy for locally advanced cervical cancer using time-driven activity-based costing. Int J Radiat Oncol Biol Phys 2018;100:88-94.

21 Ma TM, Harkenrider MM, Yashar CM, et al. Understanding the underutilization of cervical brachytherapy for locally advanced cervical cancer. Brachytherapy 2019;18:361-9.

22 Toita $\mathrm{T}$, Ohno $\mathrm{T}$, Ikushima $\mathrm{H}$, et al. National survey of intracavitary brachytherapy for intact uterine cervical cancer in Japan. J Radiat Res 2018;59:469-76.
23 Hubbard A. Radiation oncology's role in the next chapter of payment reform. Am J Manag Care 2021;27:SP63-SP64.

24 Borras JM, Lievens Y, Corral J. Tackling reimbursement for radiation oncology and cancer surgery: challenges and options (last updated 10 Jul 2020), 2020. Available: https://www.ipaac.eu/res/file/ outputs/wp8/reimbursement-radiation-oncology-cancer-surgery.pdf [Accessed 11 Aug 2021].

25 Tagliaferri L, Vavassori A, Lancellotta V, et al. Can brachytherapy be properly considered in the clinical practice? Trilogy project: the vision of the AIRO (Italian Association of Radiotherapy and Clinical Oncology) Interventional Radiotherapy study group. J Contemp Brachytherapy 2020;12:84-9.

26 Kahn JM, Campbell SR, Albert AA, et al. \#ThislsBrachytherapy: increasing awareness of brachytherapy. Brachytherapy 2021;20:232-6.

27 Petereit D. Moving forward: 300 in 10: the American Brachytherapy Society's 10-year training strategy. ASTROnews. Spring, 2019. Available: https://www.astro.org/ASTRO/media/ASTRO/News\% 20and\%20Publications/ASTROnews/PDFs/2019_Spring_ ASTROnews.pdf [Accessed 11 Aug 2021].

28 Williams VM, Mansoori B, Young L, et al. Simulation-based learning for enhanced gynecologic brachytherapy training among radiation oncology residents. Brachytherapy 2021;20:128-35.

29 Abdel-Wahab M, Grover S, Zubizarreta EH, et al. Addressing the burden of cervical cancer through IAEA global brachytherapy initiatives. Brachytherapy 2020;19:850-6.

30 Miriyala R, Mahantshetty U. Brachytherapy in cervical cancer radiotherapy during COVID-19 pandemic crisis: problems and prospects. J Contemp Brachytherapy 2020;12:290-3.

31 Datta NR, Datta S, Samiei M. Strategies to maximize available resources with minimum cost escalation for improving radiation therapy accessibility in the post-coronavirus disease 2019 era: an analysis for Asia. Adv Radiat Oncol 2021;6.

32 Kirchheiner K, Czajka-Pepl A, Ponocny-Seliger E, et al. Posttraumatic stress disorder after high-dose-rate brachytherapy for cervical cancer with 2 fractions in 1 application under spinal/epidural anesthesia: incidence and risk factors. Int J Radiat Oncol Biol Phys 2014;89:260-7

33 Atun R, Jaffray DA, Barton MB, et al. Expanding global access to radiotherapy. Lancet Oncol 2015;16:1153-86.

34 Datta NR, Samiei M, Bodis S. Radiation therapy infrastructure and human resources in low- and middle-income countries: present status and projections for 2020. Int J Radiat Oncol Biol Phys 2014;89:448-57.

35 Bishr MK, Zaghloul MS. Radiation therapy availability in Africa and Latin America: two models of low and middle income countries. Int $J$ Radiat Oncol Biol Phys 2018;102:490-8.

36 Grover S, Gudi S, Gandhi AK, et al. Radiation oncology in India: challenges and opportunities. Semin Radiat Oncol 2017;27:158-63.

37 Wang L, Lu JJ, Yin W, et al. Perspectives on patient access to radiation oncology facilities and services in mainland China. Semin Radiat Oncol 2017;27:164-8.

38 Apás Pérez De Nucci A, Minig L, Perrotta M. Patterns of cervical cancer care in Argentina: applying ASCO recommendations adjusted by local resources. Gynecol Oncol Rep 2017;21:61-6.

39 Chopra S, Shukla R, Budukh A, et al. External radiation and brachytherapy resource deficit for cervical cancer in India: call to action for treatment of all. J Glob Oncol 2019;5:1-5.

40 Abdel-Wahab M, Rosenblatt E, Holmberg O, et al. Safety in radiation oncology: the role of international initiatives by the International Atomic Energy Agency. J Am Coll Radiol 2011;8:789-94.

41 International Atomic Energy Agency. Radiotherapy in cancer care: facing the global challenge, 2017. Available: https://www-pub.iaea. org/MTCD/Publications/PDF/P1638_web.pdf [Accessed 11 Aug 2021].

42 Donkor A, Luckett T, Aranda S, et al. Experiences of barriers and facilitators to establishing and sustaining radiotherapy services in low- and middle-income countries: a qualitative study. Asia Pac J Clin Oncol 2020;16:e74-85.

43 Elmore S, Prajogi G, Rubio J. The global radiation oncology workforce in 2030: estimating physician training needs and proposing solutions to scale up capacity in low- and middle-income countries. App/ Rad Oncol 2019;8:10-16 https://appliedradiation oncology.com/articles/the-global-radiation-oncology-workforcein-2030-estimating-physician-training-needs-and-proposingsolutions-to-scale-up-capacity-in-low-and-middle-income-countries [Accessed 11 Aug 2021]

44 Robin TP, Grover S, Reddy Palkonda VA, et al. Utilization of a webbased conferencing platform to improve global radiation oncology education and quality-proof of principle through implementation in India. Int J Radiat Oncol Biol Phys 2019;103:276-80. 
45 Mileshkin LR, Moore KN, Barnes E, et al. Adjuvant chemotherapy following chemoradiation as primary treatment for locally advanced cervical cancer compared to chemoradiation alone: the randomized phase III OUTBACK trial (ANZGOG 0902, RTOG 1174, NRG 0274). JCO 2021;39:LBA3.

46 Faivre-Finn C, Vicente D, Kurata T, et al. Four-year survival with durvalumab after chemoradiotherapy in stage III NSCLC-an update from the PACIFIC trial. J Thorac Oncol 2021;16:860-7.

47 Colombo N, Dubot C, Lorusso D, et al. Pembrolizumab for persistent, recurrent, or metastatic cervical cancer. N Engl J Med 2021;385:1856-67.

48 Mayadev J, Nunes AT, Li M, et al. CALLA: efficacy and safety of concurrent and adjuvant durvalumab with chemoradiotherapy versus chemoradiotherapy alone in women with locally advanced cervical cancer: a phase III, randomized, double-blind, multicenter study. Int J Gynecol Cancer 2020;30:1065-70.

49 Mayadev J, Zamarin D, Deng W, et al. Anti-PD-L1 (atezolizumab) as an immune primer and concurrently with extended-field chemoradiotherapy for node-positive locally advanced cervical cancer. Int J Gynecol Cancer 2020;30:701-4.

50 Duska LR, Scalici JM, Temkin SM, et al. Results of an early safety analysis of a study of the combination of pembrolizumab and pelvic chemoradiation in locally advanced cervical cancer. Cancer 2020;126:4948-56.

51 Goel S, Duda DG, Xu L, et al. Normalization of the vasculature for treatment of cancer and other diseases. Physiol Rev 2011;91:1071-121.
52 Kunos CA, Ivy SP. Triapine radiochemotherapy in advanced stage cervical cancer. Front Oncol 2018;8:149.

53 Lux F, Tran VL, Thomas E, et al. AGulX ${ }^{\circledR}$ from bench to bedsidetransfer of an ultrasmall theranostic gadolinium-based nanoparticle to clinical medicine. Br J Radiol 2019;92:20180365.

54 International Atomic Energy Agency. Management of cervical cancer: strategies for limited-resource centres - a guide for radiation oncologists (last updated 19 Feb 2020), 2013. Available: https:// www.iaea.org/publications/8738/management-of-cervical-cancerstrategies-for-limited-resource-centres-a-guide-for-radiationoncologists [Accessed 11 Aug 2021].

55 Chuang LT, Temin S, Camacho R, et al. Management and care of women with invasive cervical cancer: American Society of Clinical Oncology resource-stratified clinical practice guideline. J Glob Oncol 2016;2:311-40.

56 Shrivastava SK, Mahantshetty U, Narayan K. Principles of radiation therapy in low-resource and well-developed settings, with particular reference to cervical cancer. Int J Gynaecol Obstet 2015;131 Suppl 2:S153-8.

57 Suneja G, Brown D, Chang A, et al. American Brachytherapy Society: brachytherapy treatment recommendations for locally advanced cervix cancer for low-income and middle-income countries. Brachytherapy 2017;16:85-94.

58 Chopra SJ, Mathew A, Maheshwari A, et al. National cancer grid of India consensus guidelines on the management of cervical cancer. $J$ Glob Oncol 2018;31:1-15. 